\title{
The Problem of Universals from the Scientific Point of View: Thomas Aquinas Should Be More Appreciated
}

\author{
Shiro Ishikawa \\ Department of Mathematics, Faculty of Science and Technology, Keio University, Yokohama, Japan \\ Email: ishikawa@math.keio.ac.jp
}

How to cite this paper: Ishikawa, S. (2022). The Problem of Universals from the Scientific Point of View: Thomas Aquinas Should Be More Appreciated. Open Journal of Philosophy, 12, 86-104.

https://doi.org/10.4236/ojpp.2022.121006

Received: December 13, 2021

Accepted: February 14, 2022

Published: February 17, 2022

Copyright $\odot 2022$ by author(s) and Scientific Research Publishing Inc. This work is licensed under the Creative Commons Attribution International License (CC BY 4.0).

http://creativecommons.org/licenses/by/4.0/

\begin{abstract}
Recently we proposed the linguistic Copenhagen interpretation of quantum mechanics, which is called quantum language or measurement theory. This theory is valid for both quantum and classical systems. Thus, we think that quantum language is one of the most powerful scientific theories, like statistics, and thus, it is the scientific completion (i.e., the destination) of dualistic idealism. If so, we can introduce the concept "progress" in the dualistic idealism. For example, we can assert that [Plato $\rightarrow$ Descartes $\rightarrow$ Kant $\rightarrow$ Wittgenstein $\rightarrow$ quantum language], where ["X" $\rightarrow$ "Y"] means that "Y" is more like quantum language than " $X$ ". In this paper, we will study the problem of universals from the perspective of quantum language (i.e., from the scientific perspective of ignoring any religious perspective). And we can be confident of the progress of both of the two time series [Plato $\rightarrow$ Anselmus $\rightarrow$ Thomas Aquinas $\rightarrow$ quantum language] and [Descartes $\rightarrow$ Thomas Aquinas $\rightarrow$ quantum language] in dualistic idealism. The reader may find it surprising that Scholastic philosophy is more scientific than Cartesian-Kantian philosophy. However, this is because Descartes gave up the pursuit of "universals" and presented dualism as a visible "mind-matter dualism" so that it could be familiar to the general public. This made the Cartesian-Kantian philosophy socially successful, but unscientific. The problem of universals has not always been clear in the long history of philosophy. The reader should be convinced that the reason is that the problem of universals has been discussed in an incomplete non-scientific dualism to this day.
\end{abstract}

\section{Keywords}

Linguistic Copenhagen Interpretation, The Problem of Universals, Scholasticism, Thomas Aquinas 


\section{Introduction}

\subsection{Quantum Language}

Recently, in refs. (Ishikawa, 1997a, 1997b, 2006, 2011), we proposed the linguistic Copenhagen interpretation (or, quantum language, measurement theory), which has a great linguistic power to describe both classical and quantum systems. Thus, we think that quantum language can be viewed as a language of science.

The location of QL (= quantum language) in the history of the world-descriptions is shown in Figure 1 (Ishikawa, 2012a, 2019b, 2021b).

As seen in Figure 1, roughly speaking, QL has the following four aspects, that is,

$\left(A_{1}\right)$ (7): the linguistic turn of quantum mechanics (Ishikawa, 1991a, 1991b, $2011,2015,2017 b)$

$\left(\mathrm{A}_{2}\right)$ 8): the dualistic turn of statistics (=dynamical system theory) (Ishikawa, 1997a, 1997b, 1998, 2000, 2008, 2012b, 2012c, 2012d)

$\left(\mathrm{A}_{3}\right)$ (10): the scientific turn of Descartes = Kant philosophy (Ishikawa, 2017a, 2018, 2019a, 2020)

$\left(\mathrm{A}_{4}\right)$ 13): the logical aspect (Ishikawa, 1998, 2020, 2021a; Ishikawa \& Kikuchi, 2021)

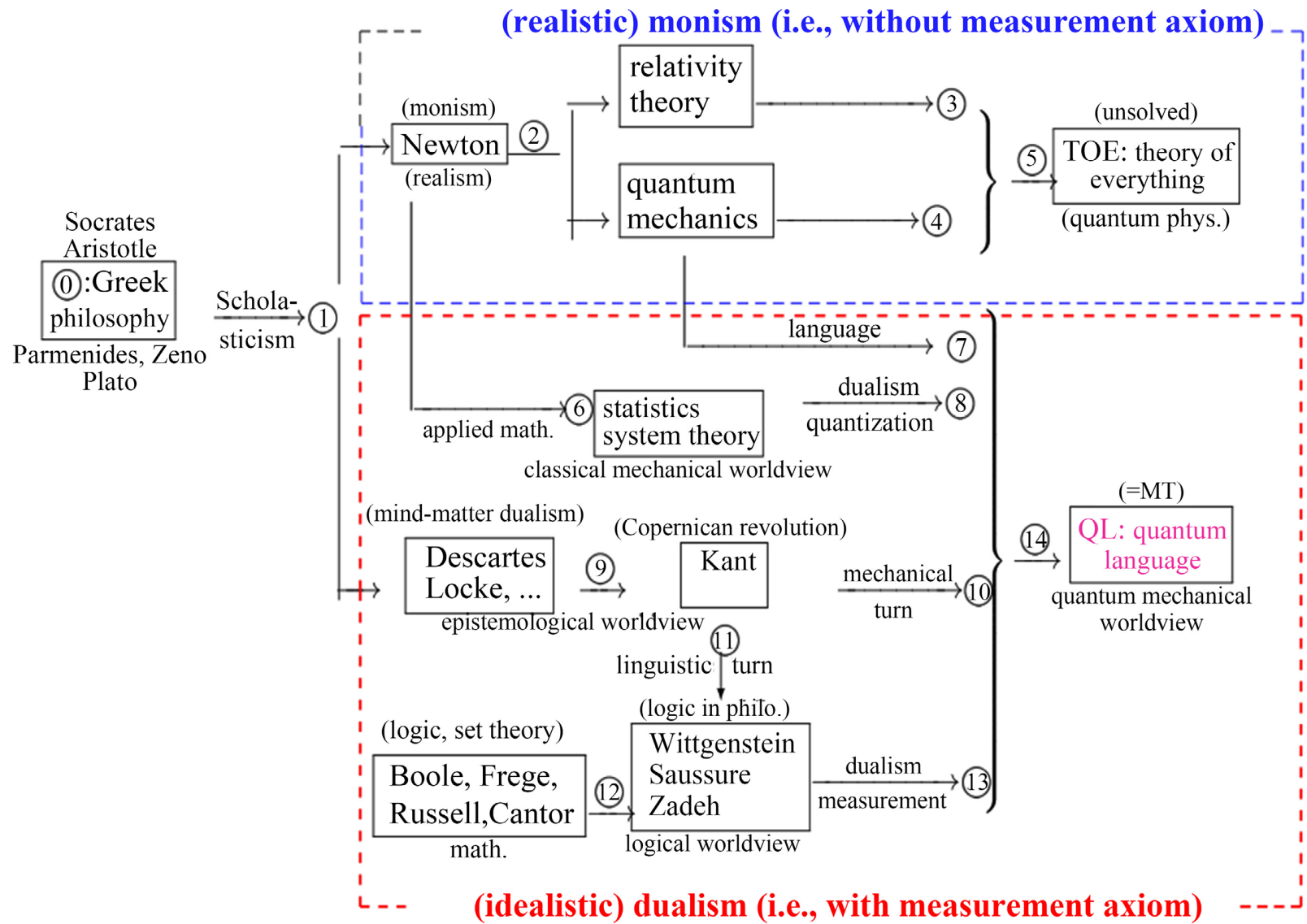

Figure 1. The history of the world-descriptions. 
Thus, we assert that QL is the scientific completion (i.e., the destination) of dualistic idealism. If so, we can use QL to rate many dualistic theories, that is, we can introduce the concept "progress" in the dualistic theories such as [" $\mathrm{X}$ " $\Rightarrow$ QL "Y"] means that "Y" is more like "QL" than " $\mathrm{X}$ ". Thus, ["X" $\Longrightarrow$ QL "Y"] can be interpreted as ["Y" is more scientific than " $\mathrm{X}$ "].

And we can assert (Ishikawa, 2021b) that

(B) Plato $\Rightarrow^{\mathrm{QL}}$ Descartes $\Rightarrow \begin{array}{lll}\mathrm{QL} & \text { Kant } & \Rightarrow^{\mathrm{QL}} \text { Wittgenstein }\end{array} \Rightarrow^{\mathrm{QL}} \mathrm{QL}$

(founder) (mind-matter dualism) (Copernican revolution) (logic) (science)

\subsection{The Purpose of This Paper}

The purpose of this paper is to bridge the gap between (1) and (1) in Figure 1. That is, we can assert that, through the problem of universals, Scholastic philosophy had progressed. Namely, we assert that

$$
\begin{aligned}
& \left(\mathrm{C}_{1}\right) \quad \text { Plato } \quad \Rightarrow \text { Anselmus } \quad \Rightarrow^{\mathrm{QL}} \quad \text { Thomas Aquinas } \\
& \text { (real world, the sun, Idea world) [[/], before individuals, [/]] [after, before, in individuals] } \\
& \Rightarrow \text { QL } \quad \text { QL }
\end{aligned}
$$

and

$$
\begin{gathered}
\left(\mathrm{C}_{2}\right) \text { Descartes } \\
\text { (mind, body, matter) }
\end{gathered} \underset{\text { [after, before, in individuals] }}{\text { Thomas Aquinas }} \underset{\text { [measured value, observable, state] }}{\mathrm{QL}}
$$

This $\left(\mathrm{C}_{2}\right)$ is surprising, but keep in mind that Scholastic philosophy is a philosophy for professionals, while Cartesian-Kantian philosophy is a philosophy written for the general public. That is, we think that $\left(\mathrm{C}_{2}\right)$ implies that Descartes chose "popularity among the masses" rather than "scientific".

This may be a natural choice if we consider that philosophy is a kind of literature.

In Section 2, we review the basics of quantum language (and the linguistic Copenhagen interpretation). And in Section 3, we discuss the problem of universals in QL. In Section 4, we study the problem of universals in Scholasticism and show the above (C). Further, in Section 5, we review the problem of universals in modern times.

\section{Review: Quantum Language $(=\mathrm{QL}=$ Measurement $T$ heory $)$}

Following refs. (Ishikawa, 1997a, 1997b, 2006, 2011), we shall review quantum language (i.e., the linguistic Copenhagen interpretation of quantum mechanics, or measurement theory), which has the following form:

$$
\text { (D) } \begin{aligned}
\mathrm{QL}(=\mathrm{Q} \text { Quantum language }) & = \\
& + \text { Axiom 1(measurement }+ \text { Axiom 2(Causality) } \\
& \text { Linguistic Copenhagen interpretation }
\end{aligned}
$$

We believe that quantum language is the only successful dualistic idealism in science.

In this paper we assume that "idealism" = "metaphysics" = "a discipline that 
cannot be verified by experiment". Mathematics is of course successful metaphysics, but it is not dualistic.

\subsection{Mathematical Preparations}

Now we briefly introduce quantum language $(=\mathrm{QL}=$ measurement theory) as follows: (For details, see (Ishikawa, 2019b)).

Consider an operator algebra $B(H)$ (i.e., the algebra of all bounded operators on a Hilbert space $H$ ) and consider a $C^{*}$ algebra $\mathcal{A}(\subseteq B(H))$ (von Neumann 1932; Sakai, 1971).

Quantum language $(=\mathrm{QL}=$ the linguistic Copenhagen interpretation) is classified as follows.

(E $\mathrm{E}_{1}$ ): quantum system theory (when $\mathcal{A}=B_{C}(H)$ )

$\left(\mathrm{E}_{2}\right)$ : classical system theory (when $\mathcal{A}=C(\Omega)$ )

That is, when $\mathcal{A}=B_{C}(H)$, the $C$-algebra composed of all compact operators on a Hilbert space $H$, the $\left(\mathrm{E}_{1}\right)$ is called quantum measurement theory (or, quantum system theory), which can be regarded as the linguistic aspect of quantum mechanics. Also, when $\mathcal{A}$ is commutative (that is, when $\mathcal{A}$ is characterized by $C(\Omega)$, the $C^{*}$ algebra composed of all continuous complex-valued functions on a compact Hausdorff space $\Omega$ (Yosida, 1980), the $\left(\mathrm{E}_{2}\right)$ is called classical measurement theory.

In this paper, for simplicity, we devote ourselves to the case $\left(\mathrm{E}_{2}\right)$, i.e., the classical QL.

Definition 1. [Observable] According to the noted idea (Davies, 1976) in quantum mechanics, an observable $O:=(X, \mathcal{P}(X), G)$ in $C(\Omega)$ is defined as follows:

1) $X$ is a finite set, $\mathcal{P}(X) \quad\left(=2^{X}\right.$, the power set of $\left.X\right)$,

2) [Additivity] $\mathrm{F}$ is a mapping from $\mathcal{P}(X)$ to $\mathrm{C}(\Omega)$ such that

a) every $\Xi \in \mathcal{P}(X), G(\Xi)$ is a non-negative element in $C(\Omega)$ such that $0 \leq G(\Xi) \leq I$,

b) $G(\varnothing)=0$ and $G(X)=I$, where 0 and $I$ is the 0 -element and the identity in $\mathrm{C}(\Omega)$ respectively.

c) $G\left(\Xi_{1}\right)+G\left(\Xi_{2}\right)=G\left(\Xi_{1} \cup \Xi_{2}\right)$ for any $\Xi_{1}, \Xi_{2} \in \mathcal{P}(X)$ such that $\Xi_{1} \cap \Xi_{2}=\varnothing$

(For the more precise explanations, see (Ishikawa, 2019b).)

\subsection{Axiom 1 [Measurement] and Axiom 2 [Causality]}

With any classical system $S$, a commutative $C$-algebra $C(\Omega)(\subseteq B(H))$ can be associated in which QL of that system can be formulated.

Axiom 0. [State, System]. A state of the system $S$ is represented by an element $\omega(\in \Omega)$. This is too basic (or, self-evident), thus it is often omitted as in (D).

Axiom 1 presented below is a kind of mathematical generalization of Born's 
probabilistic interpretation of quantum mechanics. And thus, it is a statement without reality. Now we can present Axiom 1 as follows.

Axiom 1. [=measurement axiom (Observable, Measured value, Measurement, Probability)] The measurement of the observable $O$ for the system $S$ with the state $\omega$ is denoted by $M_{C(\Omega)}\left(O:=(X, \mathcal{P}(X), G), S_{[\omega]}\right)$. An observer can obtain a measured value $x(\in X)$ by the measurement $M_{C(\Omega)}\left(O, S_{[\omega]}\right)$. And the probability that a measured value $x(\in X)$ obtained by the measurement $M_{C(\Omega)}\left(O, S_{[\omega]}\right)$ is given by $[G(\{x\})](\omega)$.

Next, we explain Axiom 2 (which is not used in this paper). Consider $C\left(\Omega_{1}\right)$ and $C\left(\Omega_{2}\right)$. And consider a homomorphism $\Phi_{2,1}: C\left(\Omega_{2}\right) \rightarrow C\left(\Omega_{1}\right)$, which is called a causal operator.

Axiom 2. [Causality]; The causality is represented by a causal operator $\Phi_{2,1}: C\left(\Omega_{2}\right) \rightarrow C\left(\Omega_{1}\right)$.

Remark 2. [Causal map]: A continuous map $\phi_{1,2}: \Omega_{1} \rightarrow \Omega_{2}$ is called a causal map, if it satisfied that $\left[\Phi_{2,1}\left(f_{2}\right)\right]\left(\omega_{1}\right)=f_{2}\left(\phi_{1,2}\left(\omega_{1}\right)\right) \quad\left(\forall f_{2} \in C\left(\Omega_{2}\right)\right.$, $\left.\forall \omega_{1} \in \Omega_{1}\right)$. Thus, "causal operator" and "causal map" are equivalent. In monism, we usually use "causal map $\phi_{1,2}: \Omega_{1} \rightarrow \Omega_{2}$ " instead of "causal operator $\Phi_{2,1}: C\left(\Omega_{2}\right) \rightarrow C\left(\Omega_{1}\right)$ ”.

\subsection{Linguistic Copenhagen Interpretation}

It is well known (Howard, 2004) that the Copenhagen interpretation of quantum mechanics has not been established yet. For example, about the right or wrong of the wave function collapse, opinions are divided in the Copenhagen interpretation. Also, the meaning of the errors in Heisenberg's uncertainty relation has yet to be clarified (Ishikawa, 1991a, 1991b). Thus, the Copenhagen interpretation is often called "so-call Copenhagen interpretation". However, we believe that the linguistic Copenhagen interpretation of quantum language (D) (i.e., both quantum $\left(\mathrm{E}_{1}\right)$ and classical $\left(\mathrm{E}_{2}\right)$ ) is uniquely determined. For example, for the quantum linguistic opinion about the wave function collapse, see (Ishikawa, 2015).

Now we explain the linguistic Copenhagen interpretation in what follows. In the above, Axioms $0 \& 2$ are kinds of spells, (i.e., incantation, magic words, metaphysical statements, idealistic statement), and thus, it is nonsense to verify them experimentally. That is because QL is a mathematical generalization of physics (i.e., quantum mechanics). Therefore, what we should do is not "to understand" but "to use".

After learning Axioms $0 \& 2$ by rote, we must improve how to use them through trial and error. We may do well even if we do not know the linguistic Copenhagen interpretation (=the manual to use Axioms 0 \& 2). However, it is better to know the linguistic Copenhagen interpretation, if we would like to 
master quantum language early. We believe that the linguistic Copenhagen interpretation is the true Copenhagen interpretation, which does not belong to physics.

Let us start from Figure 2.

In Figure 2, we remark:

$\left(F_{1}\right)$ (a): it suffices to understand that "interfere" is, for example, "apply light". (b): the reaction

(C): perceive it

That is, "measuring instrument looks into a system and pass it on to us." However,

$\left(\mathrm{F}_{2}\right)$ in measurement theory (=quantum language), "interaction" must not be emphasized.

Therefore, to avoid confusion, it might better to omit the interaction “(a) (b) and (C)" in Figure 2.

After all, we think that:

$\left(\mathrm{F}_{3}\right)$ there is no measured value without observer (i.e., "I", "mind").

Thus, we consider that measurement theory is composed of three keywords: "observer (measured value)", "observable", "state".

\begin{tabular}{lcc}
\multicolumn{2}{c}{ universal(a) } & universal(b) \\
Measured value, & observable (=measuring instrument), & state \\
(I, observer, mind) & (body (=sensory organ), eye, telescope, the North Star) & (matter)
\end{tabular}

Hence, quantum language is based on dualism, i.e., a kind of mind-matter dualism.

Assertion 3. [Linguistic Copenhagen Interpretation] In the above three, "observable (=measuring instrument)" may be the most difficult to understand. For example, if a compass is a directional measuring device, then the North Star can be also regarded as a directional measuring device.

The basics of the linguistic Copenhagen interpretation are described below.

$\left(\mathrm{G}_{1}\right)$ Only one measurement is permitted.

Thus, the state must be constant and only one. And therefore, the state after a measurement is meaningless since it cannot be measured any longer. Thus, the collapse of the wavefunction is prohibited (cf. (Ishikawa, 2011, 2015); projection

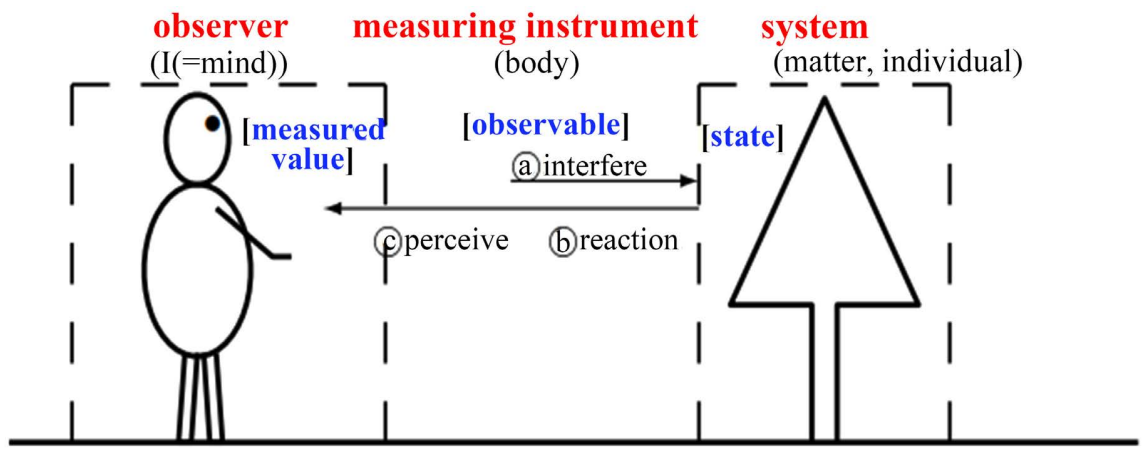

Figure 2. [Descartes Figure]: Image of "measurement (=(a), b), (c)". 
postulate). We are not concerned with anything after measurement. Strictly speaking, the phrase "after the measurement" should not be used. Also, the causality should be assumed only in the side of system, however, a state never moves. Thus, the Heisenberg picture should be adopted, and thus, the Schrödinger picture should be prohibited.

$\left(\mathrm{G}_{2}\right)$ "Observer" and "system" are completely separated. Hence, the measurement $M_{C(\Omega)}\left(O, S_{[\omega]}\right)$ does not depend on the choice of observers. That is, any proposition in quantum language is not related to "observer" (="I"), therefore, there is no "observer's space and time" in quantum language. And thus, there is no tense (i.e., past, present, future). Simply put, it is safe not to use "I, now, here".

$\left(\mathrm{G}_{3}\right)$ there is no probability without measurements (Ishikawa, 1997a, 1997b, $1998,2000,2008,2012 b, 2012 c)$, These are related to (8) in Figure 1).

$\left(\mathrm{G}_{4}\right)$ Leibniz's relationalism concerning space-time (e.g., time should be regarded as a parameter), (Ishikawa, 2018). Thus, the concept of time is created using Axiom 2 and so on.

\section{The Problem of Universals in Science}

\subsection{General Theory: Problem of Universals in Science}

The problem of universals is as follows.

Problem 4. [The prototype of the problem of universals] So-called "Problem of universals" is as follows.

(H) It is certain that Mx. Smith, Mx. White, Mx. Brown, etc. exist as matters (i.e., individuals). Then, we have the following problem: Do "universals" (i.e., "Honesty", "Optimism", "Kindness", "Female", "Intelligence”, etc.) exist?

Let us solve this problem in what follows. If we study the problem of universals from the scientific point of view, we must first answer the following two questions:

$\left(I_{1}\right)$ Under what worldview should the problem of universals be discussed?

$\left(\mathrm{I}_{2}\right)$ What is "universal"?

For $\left(\mathrm{I}_{1}\right)$, we think as follows. We answer the above as follows.

$\left(\mathrm{J}_{1}\right)$ We will discuss the problem of universals in dualistic worldview and monistic worldview, which should be formulated mathematically.

Also, for $\left(\mathrm{I}_{2}\right)$, we prepare the following definition:

Definition 5. [Universal] Assume a worldview. Then,

$\left(\mathrm{J}_{2}\right)$ "universal" is defined by the fundamental keyword with mathematical expressions in the worldview.

(Therefore, a worldview without "universals" (e.g., Kant's epistemology) cannot be mathematically grounded.)

For example, in dualistic worldview (i.e., QL, quantum mechanics) we have following keywords in QL (=Axioms $0,1,2)$ :

$\left(\mathrm{K}_{1}\right)$ observer, measured value $(x \in X \equiv\{y, n\})$, observable 
$(O:=(X, \mathcal{P}(X), G))$, measurement $M_{C(\Omega)}\left(O, S_{[\omega]}\right)$, state $(\omega)$, matter, probability $([G(\{y\})](\omega),[G(\{n\})](\omega))$, causality, causal operator $\left(\Phi_{2,1}: C\left(\Omega_{2}\right) \rightarrow C\left(\Omega_{1}\right)\right)$, etc.

Among these, universals (i.e., the ones that have mathematical expressions and are fundamental) are as follows.

$\left(\mathrm{K}_{2}\right)$ measured value $(x \in X)$, observable $(O:=(X, \mathcal{P}(X), G))$, state $(\omega)$, causal operator $\left(\Phi_{2,1}: C\left(\Omega_{2}\right) \rightarrow C\left(\Omega_{1}\right)\right)$ where "measurement $M_{C(\Omega)}\left(O, S_{[\omega]}\right)$ " is not considered "fundamental" since it is too complicated (i.e., it consists of "state", "observable" and "measured value").

Also, among $\left(\mathrm{K}_{2}\right)$, the ones related to "Honesty" etc. are as follows.

$\left(\mathrm{K}_{3}\right)$ measured value $(x \in X)$, observable $(O:=(X, \mathcal{P}(X), G))$, state $(\omega)$ which is the dualistic answer to Problem 4.

Further, in monistic worldview (i.e., worldview without Axiom 1 (= measurement axiom), e.g., Newtonian mechanics, dynamical system theory (without measurement equation)), universals are as follows.

$\left(\mathrm{L}_{1}\right)$ state $(\omega)$, causal map $\phi_{1,2}: \Omega_{1} \rightarrow \Omega_{2}$

Also, among $\left(\mathrm{L}_{1}\right)$, the ones related to "Honesty" etc. are as follows.

$\left(\mathrm{L}_{2}\right)$ state $(\omega)$ which is the monistic answer to Problem 4.

Remark 6. 1) Definition 5 is essential in our discussion about the problem of universals. Only quantum language and Newtonian mechanics have a clear definition of universals. The absence of Definition $\mathbf{5}$ has made the argument of the conventional philosophy as well as my preprint (Ishikawa, 2021b) less clear.

2) Note that space and time are keywords in Newtonian mechanics. But they are not keywords in quantum language. Thus, in quantum language, space and time must be constructed using keywords in quantum language (see di) "the Leibniz $=$ Clarke correspondence" in Section 4.3 later).

\subsection{Detailed Discussion; Problem of Universals in Science}

\subsection{1. [Dualistic Answer to Problem 4]}

Consider Problem 4 in dualistic worldview.

Let $\Omega$ be the compact state space, in which every human's state is assumed to be represented. Let $m_{H}: \Omega \rightarrow[0,1]$ [resp. $m_{O}: \Omega \rightarrow[0,1]$ ] be the membership function of "Honesty" [resp. "Optimism"] (see Figure 3) (Zadeh, 1965).

Here, assume that the value $m_{H}(\omega) \quad(\forall \omega \in \Omega)$ is determined as follows:

(M) [The probabilistic interpretation of QL]: Suppose a group of 100 respondents are asked the question "Is this person (with the state $\omega \in \Omega$ ) honest or not?" and $100 m_{H}(\omega)$ of the respondents answered "yes". Then, we can define the membership function $m_{H}: \Omega \rightarrow[0,1]$ concerning "Honesty". Similarly, $m_{O}: \Omega \rightarrow[0,1]$ is defined.

Further, define the observables $O_{H}=\left(\{y, n\}, P(\{y, n\}), G_{H}\right)$, $O_{O}\left(\{y, n\}, P(\{y, n\}), G_{O}\right) \quad$ (where " $y$ " = "yes", " $n$ " = "no") such that

$$
\begin{gathered}
{\left[G_{H}(\{y\})\right](\omega)=m_{H}(\omega),\left[G_{H}(\{n\})\right](\omega)=1-m_{H}(\omega)} \\
{\left[G_{O}(\{y\})\right](\omega)=m_{O}(\omega),\left[G_{O}(\{n\})\right](\omega)=1-m_{O}(\omega)}
\end{gathered}
$$




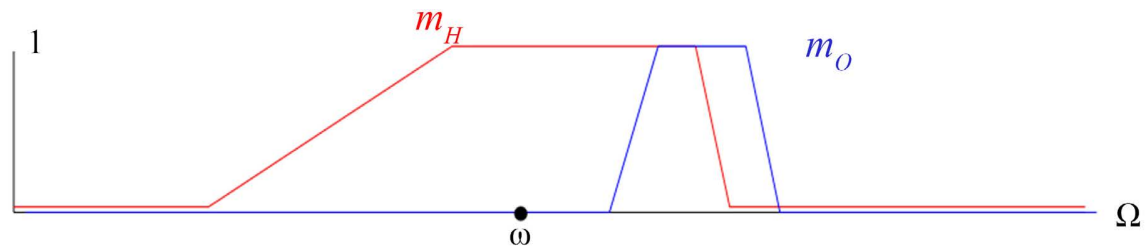

Figure 3. [Membership function $m_{H}$ of "Honesty" ( $m_{O}$ of "Optimism")].

for all $\omega \in \Omega$.

And thus, we have the following identifications:

$$
O_{H} \approx m_{H}, \quad O_{O} \approx m_{O}
$$

Therefore, we see that

(N) the probability that a measured value $y(\in X=\{y, n\})$ obtained by the measurement $M_{C(\Omega)}\left(O_{H}=\left(\{y, n\}, \mathcal{P}(\{y, n\}), G_{H}\right), S_{[\omega]}\right)$ is given by $\left[G_{H}(\{y\})\right](\omega)\left(=m_{H}(\omega)\right)$

That is, choosing one at random from a group of 100 people, you ask to him/ her the question "Is this person (with state $\omega$ ) honest or not?". Then he/she surely answers, with the probability $m_{H}(\omega)$, "This person is honest".

Thus, in the framework of Axioms 0 and 1, we can say that the measurement $M_{C(\Omega)}\left(O_{H}=\left(\{y, n\}, \mathcal{P}(\{y, n\}), G_{H}\right), S_{[\omega]}\right)$ is meaningful, that is, three important keywords (i.e., three universals) concerning "Honesty" etc. exist as follows.

(O) measured values $\{y, n\}$, observable $O_{H}$ (equivalently, membership function $m_{H}: \Omega \rightarrow[0,1]$, state $\omega$

This is our conclusion in scientific dualism (i.e., QL).

\subsection{2. [Monistic Answer to Problem 4]}

However, there is another idea as follows. Let us start from Axioms 0 and Axiom 2 (or to be more specific, Newtonian mechanics), that is, we start from the monistic worldview. Then, in this case, only "state $\omega$ " (or $S_{[\omega]}$ ) is meaningful. Thus,

$\left(\mathrm{P}_{1}\right)$ the universal concerning "Honesty" etc. is only "state $\omega$ "

For example, assume that some say that

$\left(\mathrm{P}_{2}\right)$ "A person with the state $\omega$ is honest (i.e., $m_{H}(\omega)=1$ )"

However, without Axiom 1 (i.e., the probabilistic interpretation of QL), the statement $\left(\mathrm{P}_{2}\right)$ is nothing more than "sound."

\subsection{Summary}

Thus, we see:

Answer 7. [Answer to Problem 4] We answer as follows

$\left(\mathrm{Q}_{1}\right) \mathrm{QL}$ (i.e., dualism= worldview including Axiom 1 (measurements)) has several key-words such as "observer", "measured value $(x \in X=\{y, n\})$ ", "observable

$(O:=(X, \mathcal{P}(X), G))$ ), "measurement $\left(M_{C(\Omega)}\left(O, S_{[\omega]}\right)\right)$ ", "state $(\omega)$ ", "matter",

“probability ()", "causality", "causal operator $\left(\Phi_{2,1}: C\left(\Omega_{2}\right) \rightarrow C\left(\Omega_{1}\right)\right)$ ", etc. 
However, universals concerning "Honesty" etc. are following three:

"measured value $(x \in X)$ ", "observable $(O:=(X, \mathcal{P}(X), G))$ ", "state $(\omega)$ "

This is the same as the formula (2), that is,

\begin{tabular}{ccc}
\multicolumn{1}{c}{ universal(a) } & universal(b) \\
Measured value, & observable (=measuring instrument), & state \\
(I, observer, mind) & (body(= sensory organ), eye, telescope, the North Star) & (matter)
\end{tabular}

$\left(\mathrm{Q}_{2}\right)$ Monism (i.e., worldview without Axiom 1 (measurements)) has several key words such as system, state $(\omega)$, causality, causal map $\left(\phi_{1,2}: \Omega_{1} \rightarrow \Omega_{2}\right)$, etc.

However, universals concerning "Honesty" etc. are following one: state $(\omega)$

Remark 8. It is generally believed that the problem of universals is difficult to understand. The reason for this is that the problem of universals can only be fully understood within the context of scientific dualism (i.e., Newtonian mechanics and QL). And this is because the discovery of scientific dualism (that is, the discovery of quantum language (or quantum mechanics)) is only recent.

\section{The Problem of Universals in History of Philosophy}

\subsection{Dualism and Monism in Scholasticism}

As mentioned in Definition 5 in the previous section, "universal" can only be accurately defined under a scientific worldview. Therefore, it is easy to infer that the universal argument has a history of confusion. In this section, we will review such confusion.

Let us start from Table 1:

Table 1. Universals in worldviews (monism and dualism.

\begin{tabular}{|c|c|c|c|c|}
\hline l & I & [universal(a)] & [universal(b)] & [universal(b)] \\
\hline \multirow{6}{*}{$\begin{array}{l}\text { (realistic) } \\
\text { monism }\end{array}$} & Aristotle & & & $\begin{array}{c}\text { Hyle } \\
\text { [eidos] }\end{array}$ \\
\hline & $\begin{array}{c}\text { Abelard } \\
(1079-1142)\end{array}$ & & & $\begin{array}{l}\text { indivisible } \\
\text { [universal] }\end{array}$ \\
\hline & Ockham & & & indivisible \\
\hline & $(1285-1347)$ & & & [universal] \\
\hline & Newton & & & point mass, matter \\
\hline & (scientific theory) & & & [state] \\
\hline \multirow{4}{*}{$\begin{array}{l}\text { (idealistic) } \\
\text { dualism }\end{array}$} & $\begin{array}{c}\text { Plato } \\
\text { (Analogy of the sun) }\end{array}$ & Actual world & Idea & Idea world \\
\hline & $\begin{array}{l}\text { Augustinus } \\
(354-430)\end{array}$ & city of this world & church & City of God \\
\hline & $\begin{array}{c}\text { Anselmus } \\
(1033-1109)\end{array}$ & (?) & [universal] & indivisible \\
\hline & $\begin{array}{c}\text { Thomas Aquinas } \\
(1225-1274)\end{array}$ & $\begin{array}{c}\text { human } \\
\text { [universal(a)] }\end{array}$ & $\begin{array}{c}\text { divine } \\
{[\text { universal(b)] }}\end{array}$ & $\begin{array}{c}\text { Indivisible } \\
\text { [universal(i)] }\end{array}$ \\
\hline
\end{tabular}




\section{Continued}

\begin{tabular}{|c|c|c|c|}
\hline $\begin{array}{c}\text { Descartes } \\
(1596-1650)\end{array}$ & mind & body & matter \\
\hline $\begin{array}{l}\text { John Locke } \\
(1632-1704)\end{array}$ & mind & $\begin{array}{c}\text { sensory } \\
\text { [secondary quality] }\end{array}$ & $\begin{array}{c}\text { matter } \\
\text { [primary quality] }\end{array}$ \\
\hline $\begin{array}{c}\text { Kant } \\
(1724-1804)\end{array}$ & brain & cognition & thing-in-itself \\
\hline $\begin{array}{c}\text { statistics } \\
\text { (scientific theory) }\end{array}$ & $\begin{array}{l}\text { trial person } \\
\text { [sample] }\end{array}$ & $\begin{array}{c}\text { trial } \\
{[?]}\end{array}$ & $\begin{array}{l}\text { population } \\
\text { [parameter] }\end{array}$ \\
\hline $\begin{array}{c}\mathrm{QL} \\
\text { (scientific theory) }\end{array}$ & $\begin{array}{c}\text { observer } \\
\text { [measured value] }\end{array}$ & $\begin{array}{c}\text { measuring } \\
\text { instrument } \\
\text { [observable] }\end{array}$ & $\begin{array}{l}\text { System } \\
\text { [state] }\end{array}$ \\
\hline
\end{tabular}

It is a matter of course that philosophy has a lot of aspects. However, I simply think philosophy is to answer, "What is a dualism?", or equivalently," What is Plato's Idea?" In what follows, the reader will see that the meaning of "universal" is clear only in Newtonian mechanics (=scientific monism) and quantum language (=scientific dualism), and that in all other cases the meaning of "universal" is ambiguous.

In Table 1, please note the following:

$\left(\mathrm{R}_{1}\right)$ Anselmus first instinctively understood the meaning of "universal." His "universal" corresponds to the "observable" of quantum language. His discovery, like that of Thomas, is a milestone in the history of dualism.

$\left(\mathrm{R}_{2}\right)$ Thomas Aquinas found three "universals". This is one of the greatest accomplishments in the history of dualism. I do not know the details of how he discovered this. It may be "compromise." However, in science, "results" are everything, and "how" is unimportant.

$\left(\mathrm{R}_{3}\right)$ It is well known that Descartes studied Scholastic philosophy intensely. However, Descartes avoided the incomprehensible "universal" argument in his philosophy. His strategy was a huge success. As a result, the popularization of philosophy progressed, and it blossomed as Descartes-Kant's epistemology. But this epistemology was like "brain science without experimentation", which is the exact opposite of science. I don't know Descartes' true intentions, but as it turns out, his achievement was to promote the "popularization" rather than the "scientification" of philosophy. Nevertheless, I insist on (B). The reason is "Kant's Copernican Revolution", see (Ishikawa, 2021b) for details

$\left(\mathrm{R}_{4}\right)$ I think John was concerned about Descartes' removal of the "universal".

$\left(\mathrm{R}_{5}\right)$ Even statistics couldn't find "universal (=observable)".

\subsection{The Problem of Universals in Scholastic Philosophy}

\subsubsection{Plato and Augustinus (354-430); Dualism}

Plato's Idea theory can be read in any way and cannot be categorically stated. However, in his famous "Analogy of the Sun", he says "Good = the sun", so he 
thinks that Idea (i.e., universal(b) (=observable)) is a bridge between the idea world and the real world. Recall Remark 3, in which we mention that the North Star can be regarded as a kind of measuring instrument.

Augustinus (354-430), the greatest Catholic priest, adopted Plato's Idea theory to reinforce Christianity as shown in Table 2.

Here, it should be noted that "church" is a bridge between "city of this world" and "City of God". Augustinus' theory is too visible since this is a theory for Christians, written in a way that everyone can understand.

However, Augustinus' dualism is rather religious (i.e., good and evil dualism), not scientific. And thus, I do not think that Augustinus' theory is more like quantum language than Plato's Idea theory.

Augustine's plan succeeded and the honeymoon era between Christianity and Plato's philosophy lasted for more than 500 years.

\subsubsection{Aristotelian Philosophy Flowed in via Islam}

Regarding monism, Aristotle is the founder and Newton is the consummator. We have a good understanding of Newtonian mechanics. In other words, Newtonian mechanics is the analysis of motion in the state (=(position, velocity)) of a point mass (=particle). Therefore, Aristotle's "hyle" and "eidos" can be respectively considered like the "particle" and "state" of Newtonian mechanics. Clearly Aristotelian philosophy flowed in via Islam. Plato's philosophy, which is a dualistic and idealistic worldview, and Aristotelian philosophy, which is a monistic and realistic worldview, are like water and oil (or, grafting a bamboo to a tree), and thus, naturally it was confusing. This confusion is the problem of universals (Table 3).

\subsubsection{Anselmus (1033-1109); Dualism}

First, Anselmus of England, the father of Scholasticism, argued that

(S) universals are real and exist before individuals, and preached realism (i.e., conceptual realism, in this paper it is also called dualistic idealism despite the risk of confusing you). We appreciate (S) from a scientific point of view. Because Plato is fairy tale and Augustine is too religious.

Table 2. (сTable 1): Plato and Augustinus.

\begin{tabular}{cccc}
\hline $\begin{array}{c}\text { Plato } \\
\text { (Allegory of the sun) } \\
\begin{array}{c}\text { Augustinus } \\
(354-430)\end{array}\end{array}$ & Actual world & idea & Idea world \\
& City of this world & church & City of God
\end{tabular}

Table 3. (сTable 1): Aristotle and Newton.

\begin{tabular}{cc}
\hline Aristotle & hyle \\
& [eidos] \\
Newton & Point mass(matter) \\
(scientific theory) & [state] \\
\hline
\end{tabular}




\subsubsection{Abelard (1079-1149); Monism}

Since "eidos" is usually regarded as "Aristotle's Idea", it is natural to consider that

$\left(\mathrm{T}_{1}\right)$ universals are in individuals

Therefore, it is reasonable that Roscellinus (1050-1125), Abelard (1079-1142) and others proposed an argument known as nominalism argued in what follows:

$\left(\mathrm{T}_{2}\right)$ universals (in the sense of Anselmus) are merely nominal terms or "sound"

\subsubsection{Thomas Aquinas (1225-1274); Dualism}

It is usually said that Thomas Aquinas (1225-1274) proposed to integrate conceptual realism (=dualistic idealism) and nominalism (=monistic realism) such as:

$\left(\mathrm{U}_{1}\right)$ universals exist "before individuals" in the divine intellect, "in individuals" in the world, and "after individuals" in the human intellect, which not inferior to Cartesian mind-matter dualism. This idea became orthodox even in the Roman Catholic Church.

$\left(\mathrm{U}_{2}\right)$ The reader should compare this $\left(\mathrm{U}_{1}\right)$ and "(a) $\rightarrow$ (b) $\rightarrow$ (C) in $\left(\mathrm{F}_{1}\right)$ " and appreciate their similarities.

Thus, we assert that

$$
\begin{aligned}
& \left(\mathrm{U}_{3}\right)\left(=\left(\mathrm{C}_{1}\right)\right) \quad \text { Plato } \Rightarrow{ }^{\mathrm{QL}} \quad \text { Anselmus } \quad \mathrm{QL}^{\mathrm{L}} \quad \text { Thomas Aquinas } \\
& \text { (real world, the sun, Idea world) [[/], before individuals, [/]] [after, before, in individuals] } \\
& \Rightarrow \text { QL } \quad \text { QL } \\
& \text { [measured value, observable, state] }
\end{aligned}
$$

Also, note that Descartes gave up on the pursuit of universals. Thus, we consider that

$$
\begin{aligned}
\left(\mathrm{U}_{4}\right)(= & \left.\left(\mathrm{C}_{2}\right)\right) \text { Descartes } \\
\text { (mind, body, matter) } & \text { [after, before, in individuals] } \\
\text { [measured value, observable, state] } & \text { Thomas Aquinas }
\end{aligned}
$$

To date, universal problems have been discussed without quantum language. Therefore, I think that many people do not know $\left(U_{4}\right)$ and Thomas has been underestimated.

\subsubsection{Ockham (1285-1347); Monism}

In the 14th century, however, William Ockham and others revived nominalism (=monistic worldview), which led to the emergence of modern thought that abolished conceptual thinking and sought truth through observation and experimentation.

Nominalism was very helpful in enlightening Aristotelian philosophy. As shown in Figure 1, we think that monism and dualism are not mutually exclusive but coexist. However, under the trend that the correct answer to the problem of universals is Newtonian mechanics, nominalism has somehow become dominant, and this continues to this day.

Remark 9. [Why is Descartes Kant's philosophy not scientific than Scholastic 
philosophy?]

The following is my fiction. Therefore, please let me know if I am mistaken.

Schola philosophy was a philosophy for experts. With the Age of Discovery came the Age of Scientific Revolution, and the general public began to have some power. With the invention of the printing press by Gutenberg, there was a demand for a philosophy for the general public. Therefore, Descartes proposed a philosophy that eliminated the esoteric "universal" from Scholastic philosophy. This is Descartes' dualism of matter and mind. Descartes' strategy was a great success, and the epistemology of Descartes-Kant blossomed. However, philosophy in the age of scientific revolution does not necessarily mean that it is scientific. In fact, the epistemology of Descartes-Kant is almost "brain science without experiments".

Nevertheless, I insist on (B). That is,

$$
\underset{\text { (founder) }}{\text { Plato }} \underset{\text { (mind-matter dualism) }}{\Rightarrow} \underset{\text { (Copernican revolution) }}{{ }^{\mathrm{QL}}} \underset{\text { (logic) }}{\text { Descartes }} \underset{\text { (science) }}{\Rightarrow}
$$

The reason is "Kant's Copernican Revolution", see (Ishikawa, 2021b) for details Since philosophy is also a kind of literature, it must be supported by the general public rather than experts.

This trend has continued to the present day. For example, even the philosophy of science is structured as a theory that is supported more by the general public than by the scientists. For my proposal of the philosophy of science, see (Ishikawa, 2019a).

Remark 10. [The quantum linguistic solution of "mind-body problem"]: There are many findings in Table 1. Despite the discovery of "universal" by Scholasticism, Descartes Kant's epistemology ignored it. As a result, Descartes Kant's philosophy has become a discipline like "brain science without experiments." For example, many philosophers have become enthusiastic about so-called "mindbody problem", that is,

$\left(\mathrm{V}_{1}\right)$ what is the relationship between "mind", "body" and "matter"?

This problem remains unsolved in modern brain science.

However, the above $\left(\mathrm{V}_{1}\right)$ can be rewritten in the word "universal" as follows.

$\left(\mathrm{V}_{2}\right)$ what is the relationship between "measured value", "observable" and "state"?

And we already know the answer to this question. That is, the answer to $\left(\mathrm{V}_{2}\right)$ is Axiom 1 itself. This was discussed in (Ishikawa, 2017a).

\subsection{Problem of Universals in Modern Science}

There are various aspects to the problem of universals, but from a scientific point of view, it is a debate (comparison/examination) between monism (a world view that does not require measurement) and dualism (a world view that considers measurement to be indispensable). If so, the problem of universals is the greatest theme in 2500 years of world description history as seen in Figure 1. Historically representative discussions are listed in the following Table 4. 
Table 4. Monism vs. Dualism. (Does science Need Measurement Axiom?)

\begin{tabular}{lcc}
\hline Dispute $\backslash[\mathrm{M}]$ v.s. [D] & $\begin{array}{c}\text { Monistic worldview (realism, } \\
\text { no measurement axiom) }\end{array}$ & $\begin{array}{c}\text { Dualistic worldview (idealism, } \\
\text { measurement axiom) }\end{array}$ \\
\hline (a) motion & Hērakleitos & Parmenides \\
(5) Ancient Greek & Aristotle & Plato \\
() Problem of universals & "Nominalismus" (Abelard) & "Realismus" (Anselmus) \\
(5) space-time & Newton (Clarke) & Leibniz \\
() quantum theory & Einstein & Bohr \\
(1) philosophy of science & Carnap & Quine \\
(2) fuzzy sets & Kalman & Zadeh \\
\hline
\end{tabular}

- [About (a)] I don't know the truth about either Hērakleitos or Parmenides, but I think in what follows. Parmenides said that

(V) "There is only one," "There is no time." "There is no motion," etc.

which are like to the linguistic Copenhagen interpretation (see Section 2.3), i.e., the essence of dualism (a worldview with measurement). On the other hand, Hērakleitos insisted on intuitive things like "Everything flows." Therefore, I believe (a) is one of aspects of the problem of universals.

- [About (b) (c)] These are discussed in Section 4.2 of this paper.

- [About (d)]

A dispute over "the Leibniz $=$ Clarke correspondence" between geniuses called

"Newton (and Clarke) vs. Leibniz". Quantum language supports Leibniz (Ishikawa, 2018), although many may conclude that it is Newton's victory

- [About (e)]

The "Bohr-Einstein debate" in quantum mechanics is the biggest scientific controversy of the 20th century (Einstein et al., 1935; Bohr, 1935). In a word, this is the debate such as "Is quantum mechanics (dualism, i.e., the Copenhagen interpretation) physics?" To settle this question, I proposed a quantum language. Quantum language is a kind of mathematical generalization of quantum mechanics, and thus, this is clearly not physics. One may argue that my settlement is probably a superficial settlement. However, if there is a "real settlement", only an Einsteinian genius would be able to achieve it.

- [About $f$ ]

The Carnap Quine controversy in the philosophy of science is a controversy over the distinction between analytical and synthetic propositions. As mentioned in (Ishikawa, 2021a), quantum language is on the side of Quine. This is because the spirit of Copenhagen interpretation is that "if you don't measure, you don't know anything."

- [About g]

The "fuzzy set" proposed by Zadeh was overwhelmingly supported by some systems engineers. Zadeh's paper (Zadeh, 1965) is the most cited paper of the 20 th century. It was challenged by Kalman (the most respected systems engineer 
of his time and the proponent of the Kalman filter) on the grounds that "fuzzy sets" did not fit within the framework of dynamical systems theory (the classical dynamical worldview) (Zadeh, 2004). Now, half a century later, the fuzzy set fever seems to have died down, leaving only the impression that Kalman was right after all. If we think that "fuzzy sets" = "universals" = "binary observables".

Zadeh's proposal fits within the quantum language (quantum mechanical world view). Therefore, I think that the engineers who enthusiastically supported "fuzzy sets" at that time had a good point. From the point of view of quantum language, dynamical systems theory (classical mechanical world view) is a monistic idealism, which seems to be half-baked. However, Zadeh did not state that the value of the membership function was a probability (i.e., see (M): the probabilistic interpretation of membership functions), so he could not refute next opinion:

(W) "Fuzzy sets are merely nominal terms" which is the same as the opinion of Abelard, etc.

The scientific justification of "Fuzzy sets" is the starting point for my research (Ishikawa, 1997a, 1997b, 1998, 2000).

\section{Conclusion: Scholastic Philosophy Is More Scientific than Cartesian-Kantian Philosophy}

The following is a common belief.

(X) Thomas Aquinas is the greatest medieval philosopher, synthesizing Christian theology (Augustinus, Anselmus; dualism) and Aristotelian philosophy (Abelard; monism). That is, by tolerating Aristotelian philosophy, he laid the foundations for the development of modern science.

In terms of results, this may be the right assessment. However, uniting dualism and monism is like "grafting bamboo onto a tree", which is logically impossible. Thus, we think that $(\mathrm{X})$ above is a political and religious assessment of Thomas's achievements. From a scientific point of view, it has been misunderstood that Occam's theory is superior to Thomas's idea.

In this paper, we devote ourselves to the study of the problem of universals from a scientific point of view, and we show the scientific progress of dualism as follows.

Thus, we assert that

$$
\begin{aligned}
& \left(\mathrm{Y}_{1}\right)\left(=\left(\mathrm{U}_{3}\right)=\left(\mathrm{C}_{1}\right)\right) \quad \text { Plato } \Rightarrow{ }^{\mathrm{QL}} \quad \text { Anselmus } \quad \Rightarrow^{\mathrm{QL}} \quad \text { Thomas Aquinas } \\
& \text { (real world, the sun, Idea world) [[/], before individuals, [/]] [after, before, in individuals] } \\
& \Rightarrow \text { QL } \quad \text { QL } \\
& \text { [measured value, observable, state] }
\end{aligned}
$$

Also, we consider that

$\left(\mathrm{Y}_{2}\right)\left(=\left(\mathrm{U}_{4}\right)=\left(\mathrm{C}_{2}\right)\right)$

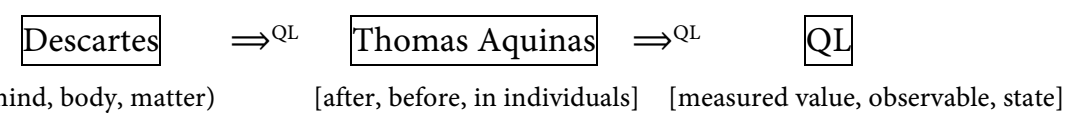

That is, we conclude that 
(Z) Thomas's philosophy is more scientific than Cartesian mind-matter dualism.

This is a scientific assessment of Thomas's achievements.

We think that Thomas's work in the formation of scientific dualism is great and should be appreciated more. We might agree to the opinion that Thomas was the first to discover dualism. Thus, we think that Thomas remains underrated. His theory is not yet accepted today from a scientific point of view. This is because the scientific dualism $(=\mathrm{QL})$ is not yet fully understood scientifically.

I am convinced that $(Z)$ is correct. However, I am not an expert in the history of philosophy, and thus, I think there are various opinions other than mine about "Why did something like $(Z)$ happen?" I hope the readers will examine my proposal from various perspectives.

Note added in proof: The symbol " $\mathrm{X} \Rightarrow{ }^{\mathrm{QL}} \mathrm{Y}$ " can be used to mean three meanings

(i): Y is closer to Axioms of QL than X.

(ii): $\mathrm{Y}$ is closer to the linguistic Copenhagen interpretation than $\mathrm{X}$.

(iii): Comprehensive judgment considering both (i) and (ii)

In this paper, I mainly used it in the sense of (i). If (ii) is assumed, then the majority of people (myself included) might agree to the following.

$$
\text { Thomas Aquinas } \Rightarrow \text { QL Descartes }
$$

In the case of (iii), opinions will be divided depending on the weight of (i) and (ii).

For further discussion, see my additional reference (Ishikawa; 2022).

\section{Conflicts of Interest}

The author declares no conflicts of interest regarding the publication of this paper.

\section{References}

Bohr, N. (1935). Can Quantum-Mechanical Description of Physical Reality Be Considered Complete? Physical Review, 48, 696-702. https://doi.org/10.1103/PhysRev.48.696

Davies, E. B. (1976). Quantum Theory of Open Systems. Academic Press.

Einstein, A., Podolosky, B., \& Rosen, N. (1935). Can Quantum-Mechanical Description of Reality Be Considered Completely? Physical Review Series, 2, 777-780. https://doi.org/10.1103/PhysRev.47.777

Howard, D. (2004). Who Invented the "Copenhagen Interpretation"? A Study in Mythology. Philosophy of Science, 71, 669-682. https://doi.org/10.1086/425941

Ishikawa, S. (1991a). Uncertainty Relation in Simultaneous Measurements for Arbitrary Observables. Reports on Mathematical Physics, 29, 257-273. https://doi.org/10.1016/0034-4877(91)90046-P https://www.sciencedirect.com/science/article/abs/pii/003448779190046P

Ishikawa, S. (1991b). Uncertainties and an Interpretation of Nonrelativistic Quantum Theory. International Journal of Theoretical Physics, 30, 401-417. https://doi.org/10.1007/BF00672888 https://link.springer.com/article/10.1007\%2FBF00672888

Ishikawa, S. (1997a). Fuzzy Inferences by Algebraic Method. Fuzzy Sets and Systems, 87, 181-200. https://doi.org/10.1016/S0165-0114(96)00035-8 
http://www.sciencedirect.com/science/article/pii/S0165011496000358

Ishikawa, S. (1997b). A Quantum Mechanical Approach to Fuzzy Theory. Fuzzy Sets and Systems, 90, 277-306. https://doi.org/10.1016/S0165-0114(96)00114-5 https://www.sciencedirect.com/science/article/abs/pii/S0165011496001145

Ishikawa, S. (1998). Fuzzy Logic in Measurements. Fuzzy Sets and Systems, 100, 291-300. https://doi.org/10.1016/S0165-0114(97)00154-1 https://www.sciencedirect.com/science/article/abs/pii/S0165011497001541

Ishikawa, S. (2000). Statistics in Measurements. Fuzzy Sets and Systems, 116, 141-154. https://doi.org/10.1016/S0165-0114(98)00280-2 http://www.sciencedirect.com/science/article/pii/S0165011498002802

Ishikawa, S. (2006). Mathematical Foundations of Measurement Theory (335 p). Keio University Press Inc. http://www.keio-up.co.jp/kup/mfomt/

Ishikawa, S. (2008). Dynamical Systems, Measurements, Quantitative Language and Zeno's Paradoxes. Far East Journal of dynamical systems, 10, 277-292. http://www.pphmj.com/abstract/3595.htm

Ishikawa, S. (2011). A New Interpretation of Quantum Mechanics. Journal of Quantum Information Science, 1, 35-42. https://doi.org/10.4236/jqis.2011.12005 http://www.scirp.org/journal/PaperInformation.aspx?paperID=7610

Ishikawa, S. (2012a). Quantum Mechanics and the Philosophy of Language: Reconsideration of Traditional Philosophies. Journal of Quantum Information Science, 2, 2-9. https://doi.org/10.4236/jqis.2012.21002 http://www.scirp.org/journal/PaperInformation.aspx?paperID=18194

Ishikawa, S. (2012b). A Measurement Theoretical Foundation of Statistics. Applied Mathematics, 3, 283-292. http://doi.org/10.4236/am.2012.33044 http://www.scirp.org/journal/PaperInformation.aspx?paperID $=18109$ \&

Ishikawa, S. (2012c). Monty Hall Problem and the Principle of Equal Probability in Measurement Theory. Applied Mathematics, 3, 788-794.

https://doi.org/10.4236/am.2012.37117 http://www.scirp.org/journal/PaperInformation.aspx?PaperID=19884

Ishikawa, S. (2012d). Ergodic Hypothesis and Equilibrium Statistical Mechanics in the Quantum Mechanical World View. World Journal of Mechanics, 2, 125-130. https://doi.org/10.4236/wjm.2012.22014 https://www.scirp.org/pdf/WJM20120200008 89783885.pdf

Ishikawa, S. (2015). Linguistic Interpretation of Quantum Mechanics; Projection Postulate. Journal of Quantum Information Science, 5, 150-155. https://doi.org/10.4236/jqis.2015.54017 http://www.scirp.org/Journal/PaperInformation.aspx?PaperID=6246416001.pff

Ishikawa, S. (2017a). A Final Solution to Mind-Body Problem by Quantum Language. Journal of Quantum Information Science, 7, 48-56.

https://doi.org/10.4236/jqis.2017.72005

http://www.scirp.org/Journal/PaperInformation.aspx?PaperID=76391

Ishikawa, S. (2017b). Bell's Inequality Should Be Reconsidered in Quantum Language. Journal of Quantum Information Science, 7, 140-154. https://doi.org/10.4236/jqis.2017.74011 http://www.scirp.org/Journal/PaperInformation.aspx?PaperID=80813

Ishikawa, S. (2018). Leibniz-Clarke Correspondence, Brain in a Vat, Five-Minute Hypothesis, McTaggart's Paradox, etc. Are Clarified in Quantum Language. Open Journal of Philosophy, 8, 466-480. https://doi.org/10.4236/ojpp.2018.85032 https://www.scirp.org/Journal/PaperInformation.aspx?PaperID=87862 
Ishikawa, S. (2019b). Linguistic Interpretation of Quantum Mechanics: Quantum [Ver.5] Language. Research Report, Dept. Math. Keio University, KSTS/RR-19/003 435p. http://www.math.keio.ac.jp/en/academic/research.html http://www.math.keio.ac.jp/academic/research_pdf/report/2019/19003.pdf

Ishikawa, S. (2020). Wittgenstein's Picture Theory in the Quantum Mechanical Worldview. Journal of Quantum Information Science, 10, 104-125. https://doi.org/10.4236/jqis.2020.104007 https://www.scirp.org/journal/paperinformation.aspx?paperid=106233

Ishikawa, S. (2021a). Fuzzy Logic in the Quantum Mechanical Worldview: Related to Zadeh, Wittgenstein, Moore, Saussure, Quine, Lewis Carroll, etc. Journal of Applied Mathematics and Physics, 9, 1583-1610. https://doi.org/10.4236/jamp.2021.97108 https://www.scirp.org/journal/paperinformation.aspx?paperid $=112972$

Ishikawa, S. (2021b). History of Western Philosophy from the Quantum Theoretical Point of View [Ver.4]. Research Report, Dept. Math. Keio University, KSTS/RR-19/ 003, 473p. http://www.math.keio.ac.jp/en/academic/research.html http://www.math.keio.ac.jp/academic/research pdf/report/2021/21001.pdf

Ishikawa, S., \& Kikuchi, K. (2021). Quantum Fuzzy Logic and Time. Journal of Applied Mathematics and Physics, 9, 2609-2622 https://doi.org/10.4236/jamp.2021.911168 https://www.scirp.org/journal/paperinformation.aspx?paperid=11297

Ishikawa, S., (2019a). Philosophy of Science for Scientists: The Probabilistic Interpretation of Science. Journal of Quantum Information Science, 9, 140-154. https://doi.org/10.4236/iqis.2019.93007 https://www.scirp.org/Journal/paperinformation.aspx?paperid=95447

Ishikawa, S. (2022). Empiricism, Rationalism, and the Kantian Synthesis from the Quantum Linguistic Point of View. (To Be Submitted). http://www.math.keio.ac.jp/ ishikawa/indexe.html

Sakai, S. (1971). C*-Algebras and $\mathrm{W}^{*}$-Algebras. In Ergebnisse der Mathematik und ihrer Grenzgbiete (Band 60). Springer Verlag.

von Neumann, J. (1932). Mathematical Foundations of Quantum Mechanics. Springer Verlag, Berlin

Yosida, K. (1980). Functional Analysis (6th ed.). Springe-Verlag.

Zadeh, L.A. (1965). Fuzzy Sets. Information and Control, 8, 338-353. https://doi.org/10.1016/S0019-9958(65)90241-X

Zadeh, L.A. (2004). Fuzzy Logic Systems, Origin, Concepts, and Trends. https://wi-consortium.org/wicweb/pdf/Zadeh.pdf 